\title{
Presence of active MRI lesions in patients suspected of non-radiographic axial spondyloarthritis with high disease activity and chance at conversion after a 6-month follow-up period
}

\author{
Tamara Rusman $^{1}$ (1) - Marie-Luise B. John ${ }^{1}$ - Mignon A. C. van der Weijden ${ }^{1} \cdot$ Bouke J. H. Boden ${ }^{2}$. \\ Carmella M. A. van der Bijl ${ }^{1}$. Stefan T. G. Bruijnen ${ }^{1}$ (D) - Conny J. van der Laken ${ }^{1}$. \\ Mike T. Nurmohamed ${ }^{1,3}$ (D) Irene E. van der Horst-Bruinsma $^{1}$
}

Received: 2 August 2019 /Revised: 4 December 2019 / Accepted: 9 December 2019 /Published online: 8 January 2020

(C) The Author(s) 2020

\begin{abstract}
Objectives The primary aim is to evaluate signs of inflammation on MRI of sacroiliac joints (SIJ)/spine in inflammatory back pain (IBP) patients suspected of nr-axSpA with high disease activity. Secondary aims are to describe the onset of new inflammatory lesions at MRI after 6 months and to evaluate gender differences in the presence of inflammation.

Method Consecutively, patients with IBP with at least two spondyloarthritis features, high disease activity (BASDAI $\geq 4$ ), and who were TNFi naïve, had a MRI of SIJ and spine. In the absence of active lesions, MRI was repeated after 6 months. MRI images were scored according to the Spondyloarthritis Research Consortium of Canada method.

Results Sixty-nine patients were included (53\% female), of whom 39\% showed signs of inflammation at the first MRI: $30.9 \%$ of the SIJ, $19.1 \%$ of the spine and $2.4 \%$ at both sites, irrespective of the CRP levels. Males more often showed inflammatory signs at the MRI of the SIJ and spine compared with females (45.5\% vs. 33.3\%). Consistently, the median SPARCC score was higher in males: for SIJ 14.0 (IQR 2.3-25.0) and for spine 11.5 (IQR 8.5-25.6). Only one patient (4.7\%) without baseline inflammatory signs showed active lesions of SIJ after 6 months.

Conclusions Almost $40 \%$ of the IBP patients suspected of nr-axSpA, with high disease activity, showed inflammatory lesions on MRI of SIJ and/or spine, which occurred more often in males compared with females. In the majority (95.3\%), an MRI without inflammatory lesions remained negative after 6 months despite high disease activity.
\end{abstract}

Key Points

- Forty percent of inflammatory back pain patients with high disease activity showed inflammatory signs on MRI of the SIJ and/or spine.

- Only 4\% of baseline MRIs without inflammatory signs at baseline conversed to an MRI with inflammatory signs after 6 months.

- Male inflammatory back pain patients with high disease activity showed more often inflammatory signs on MRI compared with females.

Keywords Gender · Inflammation · Inflammatory back pain · Magnetic resonance imaging · Spondyloarthropathy

\section{Introduction}

Irene E. van der Horst-Bruinsma

IE.vanderHorst@amsterdamumc.nl

1 Amsterdam Rheumatology \& Immunology Center, Department of Rheumatology 3a-64, VU University Medical Center, P.O. Box 7057, 1007 MB Amsterdam, The Netherlands

2 Onze Lieve Vrouwe Gasthuis (OLVG), Radiology, Amsterdam, The Netherlands

3 Reade, Rheumatology, Amsterdam, The Netherlands
According to "Assessment of Spondyloarthritis International Society (ASAS) classification criteria" (1), axial spondyloarthritis (axSpA) can be divided into two groups: patients with radiographic signs of sacroiliitis (ankylosing spondylitis, AS) and a group without radiographic sacroiliitis, the non-radiographic axial SpA (nr-axSpA) [1].

Inflammatory back pain (IBP) is an important clinical symptom for axial involvement and is present in approximately $70 \%$ of patients diagnosed with axSpA $[1,2]$.

Radiographic lesions usually develop several years after symptom onset, such as IBP, which can lead to a diagnostic 
delay of 5-10 years [3]. This may result in subsequent undesired treatment delay, in particular in patients with nr-axSpA [3]. A recent study revealed that approximately $5.1 \%$ of patients progress from $\mathrm{nr}$-axSpA to AS in a 5-year period, especially in patients positive for the HLA-B27 antigen [3, 4]. Active inflammatory lesions of the sacroiliac joints (SIJ), as defined by the ASAS group [1], contribute to an earlier diagnosis of axial SpA.

One of the challenges of the current ASAS classification criteria of axial $\mathrm{SpA}$ is the large contribution of a positive MRI of the SI joints. However, many patients with high disease activity do not show active lesions at the MRI of the SI joints; approximately 59-64\% is MRI-negative [4, 5]. Therefore, we selected patients with inflammatory back pain with at least two SpA features, who might be prone to develop axial $\mathrm{SpA}$, and repeated the MRI procedure after 6 months in case of a negative MRI (absence of active inflammation). In order to increase the chance of a positive MRI, all patients had to have a high disease activity score and should be eligible for treatment with a biological, which is in contrast with previous studies. A previous study showed an association between male gender and the chance at a positive MRI in IBP patients, but data on gender differences are scarce [4].

Therefore, the primary aim of this study was to analyse the frequency of positive MRIs (both SIJ and spine) in IBP patients suspected of nr-axSpA with high disease activity. The secondary aims were to describe the progression of a negative MRI outcome at baseline after a 6-month follow-up, to describe the possible presence of structural lesions and to assess gender differences.

\section{Materials and methods}

\section{Patients}

Patients with chronic back pain were recruited from 2009 to 2014 at the rheumatology outpatient clinics of the VU University Medical Center (VUmc), Reade/the Jan van Breemen Research Institute in Amsterdam, the Netherlands, and by the website of the Dutch ankylosing spondylitis patient society ("Dutch axial spondyloarthritis foundation"). The study complied with the Declaration of Helsinki and was approved by our local ethical committee of the VU University Medical Center (approval number medical ethical committee 2009/206), and all patients signed an informed consent before screening.

\section{Inclusion criteria}

Patients were eligible if they were $\geq 18$ years, fulfilled the Calin criteria of inflammatory back pain [6], (IBP, back pain with an insidious onset before the age of 45 years, chronic back pain persistence for at least 3 months, morning stiffness, improvement with exercise, pain at night). In addition, patients had to have at least two spondyloarthritis $(\mathrm{SpA})$ features according to the ASAS axial SpA classification criteria. They had to be either HLA-B27 positive with at least $\geq 1$ spondyloarthritis (SpA) feature or HLA-B27 negative with at least $\geq 2 \mathrm{SpA}$ features.

$\mathrm{SpA}$ features were defined according to the European Spondyloarthropathy Study Group (ESSG) criteria: asymmetrical arthritis, alternating buttock pain, dactylitis, enthesitis of the Achilles tendon or the plantar fascia, presence or history of psoriasis, inflammatory bowel disease (IBD) or acute anterior uveitis (AAU), first- or second-degree relatives with AS/psoriasis/AAU/IBD, positive response to non-steroidal anti-inflammatory drugs (NSAIDs) and raised acute phase reactants, C-reactive protein (CRP) or erythrocyte sedimentation rate (ESR) [1].

In addition, they should be eligible to treatment with a biological with a high disease activity score (Bath Ankylosing Spondylitis Disease Activity Index (BASDAI) $\geq 4$ ) and insufficient response to at least two NSAIDs (Fig. 1).

\section{Exclusion criteria}

Patients were excluded if they had definite AS according to the modified New York criteria [7], had received biological treatment or showed contraindications for treatment with a biological (Fig. 1).

\section{Rationale inclusion and exclusion criteria}

Inclusion criteria for this study were based on the algorithm of Rudwaleit et al. which had a high probability to diagnose AS early at the pre-radiographic stage in patients presenting with chronic back pain [8]. IBP was indicated as a primary entry parameter for the assessment of patients with chronic back pain, since IBP is the key symptom of axial involvement. They calculated that a probability of at least $90 \%$ can be achieved if IBP plus two to three other features was present [9].

\section{Data collection}

The following patient characteristics were collected: age, sex, age onset of back pain, duration of back pain at baseline, IBP and $\mathrm{SpA}$ features, family history of $\mathrm{SpA}$ and presence of extra-articular manifestations (EAM), such as uveitis, inflammatory bowel disease (IBD) and psoriasis, and data on the use of NSAIDs were recorded. In addition, several disease activity-related scores were recorded: BASDAI, Bath Ankylosing Spondylitis Metrology Index (BASMI), tender (TJC) and swollen (SJC) joint count and the Maastricht Ankylosing Spondylitis Enthesitis Score (MASES). 
Fig. 1 Flowchart of the inclusions. AS, ankylosing spondylitis; HLA-B27, human leukocyte antigen B27; SpA, spondyloarthritis

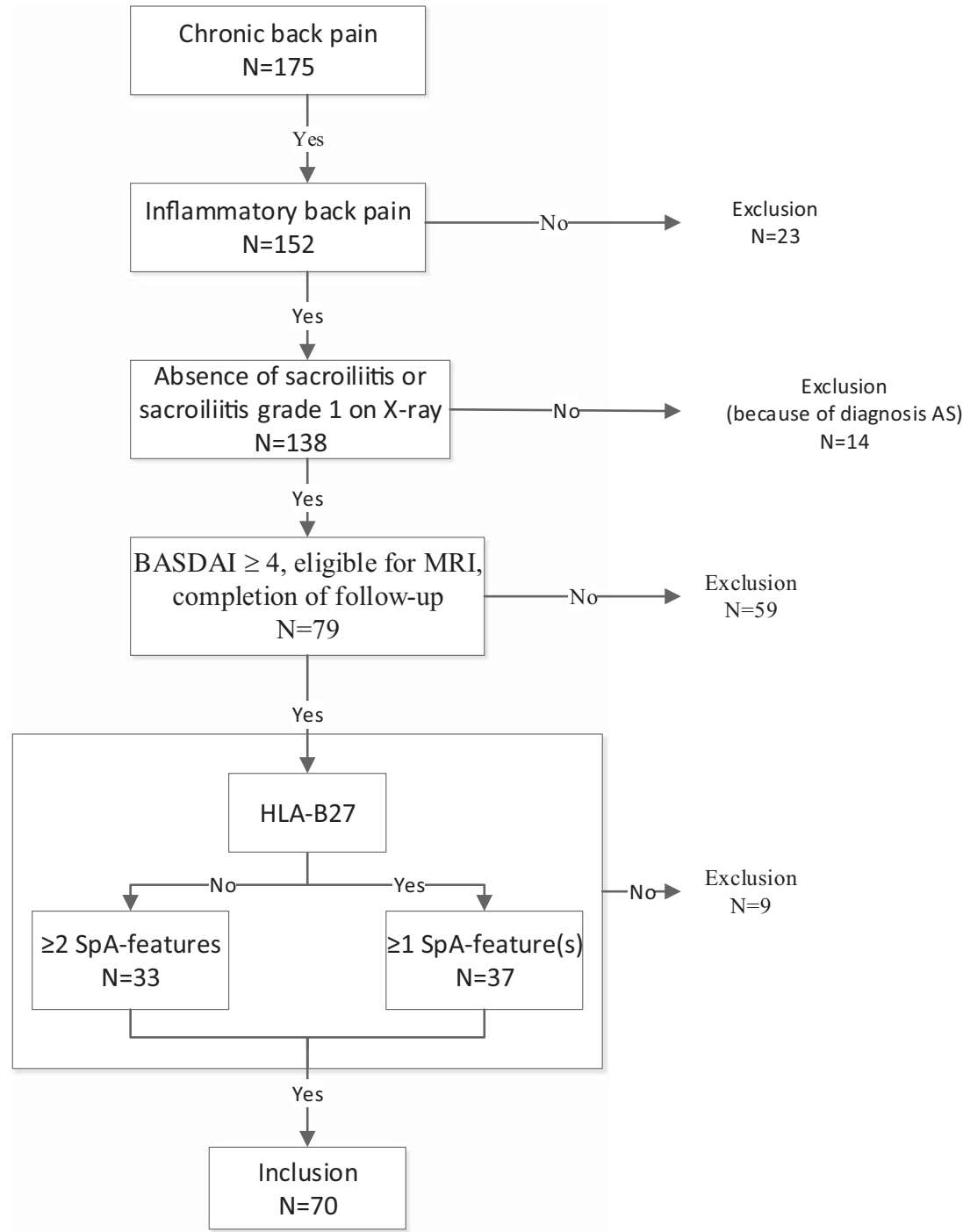

All patients were screened by a clinician and tested for the human leukocyte antigen B27 (HLA-B27) if not previously determined, C-reactive protein (CRP) and erythrocyte sedimentation rate (ESR) levels. At baseline, MRI scans of the SIJ and spine were made.

Patients without signs of inflammation at baseline MRI ("negative spine and SIJ MRI") were invited for a second MRI after 6 months. Not all patients with a negative MRI had a second MRI because some patients refused or had already started with a biological due to high disease activity $(N=18)$.

\section{MRI SIJ and spine}

Imaging was performed using a Siemens MAGNETRON Sonata 1.5-T MRI device (Siemens Medical Solutions, Erlangen, Germany). T1-weighted sequences before administration of intravenous contrast (gadolinium) T1weighted with fat suppression after intravenous contrast and short $\tau$ inversion recovery (STIR) images of the SIJ and spine were performed according to a standardized protocol in accordance with the recommendations of the European Skeletal Society of Radiology (ESSR). A detailed description of this protocol can be found in a previous article of our research group [10].

As in some patients, MRI was performed recently in another hospital before presentation at our centre; imaging was not repeated but imported into our system and revised.

MRI images of the SIJ and spine were scored by an expert radiologist of the OLVG for the presence of bone marrow edema (BME) according to the Spondyloarthritis Research Consortium of Canada (SPARCC) score for the SIJ and spine $[11,12]$. In addition, active sacroiliitis was scored according to the ASAS guidelines [13]. 


\section{Positive MRI}

A positive MRI SIJ was defined as a SPARCC score $\geq 2$ [14]. A positive MRI of the spine was defined as a SPARCC score $\geq 5$. A maximum SPARCC score for the SI joints was 72 [12] and for the spine, 108 [11].

\section{Active sacroiliitis on MRI}

Active sacroiliitis on MRI was defined as positive if a sacral inter-foraminal bone marrow signal of the SIJ (or increased signal) on a STIR image was present, which was categorized as 0 , normal signal and 1 , increased signal.

\section{Structural changes}

A descriptive analysis was performed for the presence of structural changes, such as fat infiltration in the bone marrow, bone erosions, bone spur and ankylosing. The location of these structural changes was also recorded systematically by the expert reader in the VUmc.

\section{ASAS classification criteria}

The ASAS classification criteria, consisting of the imaging arm and the clinical arm, were published after the development and start of this study. According to the ASAS classification criteria, in the clinical arm, two SpA features were required in addition to a positive HLA-B27 status. According to the ASAS classification criteria, HLA-B27negative patients were classified as axial SpA if they met the imaging criteria and one SpA feature [7]

\section{Statistical analyses}

To evaluate the possible association between MRI outcome and patient characteristics, the prevalence of patient features in patients with a positive and negative MRI (SIJ and/or spine), at any time point, was assessed. Continuous variables were analysed using the two-sided $t$ test. For categorical variables, we used the two-sided Pearson chi-square test. Changes in MRI outcome over time were evaluated descriptively. Reported were the mean, percentages, frequencies, $95 \%$ confidence interval $(\mathrm{CI})$ and range of the mean where appropriate. A $p$ value below 0.05 was considered statistically significant. If possible, gender differences in MRI outcome were assessed with independent $t$ tests and linear regression analyses in case of continuous outcomes and logistic regression analyses in case of dichotomous outcomes to adjust for sex, NSAID use at baseline and HLA-B27 status. Structural changes of the spine and SIJ were described descriptively.

\section{Results}

In total, 70 patients were included in this study (Fig. 1), of whom $37(53 \%)$ were female. The mean age at baseline was 34 years (Table 1). The first symptoms of back pain occurred at 4.7 years before diagnosis of IBP, at a mean age of 29 years. In total, 37 patients (53\%) were HLA-B27 positive, of whom 18 were female $(48.6 \%)$ and 19 were male $(51.4 \%)$. In one female patient, HLA-B27 typing was not performed.

At baseline, peripheral joint symptoms were present in $31 \%$ of patients; $42.9 \%$ presented with enthesitis, mainly of the Achilles tendon, 7\% experienced anterior uveitis and $11 \%$ had psoriasis. A positive family history of AS was present in $30 \%$ of the cases. Thirty-one percent had a raised CRP level $(\geq 5.0 \mathrm{mg} / \mathrm{l})$, and there was no significant difference in CRP between patients with a positive or negative MRI. The baseline characteristics did not show significant gender differences.

NSAIDs were used by half of the patients (52.9\%) at baseline of whom 16 patients (59.3\%) in the MRI-positive group and 20 patients $(47.6 \%)$ in the MRI-negative group.

Unfortunately, in one patient, only MRI images of the spine were available and not of the SI joints because they were performed in another centre. So complete scoring sets of the MRI scans of the SIJ were available in 69 instead of 70 patients. Some of the patients refused MRI scans of the spine, mainly due to complaints of claustrophobia, resulting in a lower number of patients with baseline MRI of the spine $(n=47)$ compared with MRI of the SIJ $(n=69)$.

\section{MRI at baseline}

Overall, in 27 of 69 patients (38.6\%), signs of inflammation were found at baseline MRI of the SIJ or spine whereas 42 patients (60.0\%) had a negative MRI of both SIJ and spine (Table 2). Twenty-one out of 69 patients $(30.4 \%)$ had a positive MRI of the SIJ, 9 out of 47 (19.1\%) of the spine, of whom three patients $(2.4 \%)$ had both. Male patients had more frequently a positive baseline MRI compared with female patients, 15 out of 33 male patients $(45.5 \%)$ vs. 12 out of 37 female patients $(33.3 \%)(\mathrm{OR}=0.58,95 \% \mathrm{CI}[0.2 ; 1.5], p=$ 0.26 ) (Table 1). Imaging of the SIJ was repeated in 21 of the 41 patients who had a negative baseline MRI (51.2\%), of whom only one patient conversed, showing new inflammatory signs at follow-up. Imaging of the spine was repeated in 15 out of 28 patients with a negative baseline MRI of the spine (53.6\%), of whom none showed new lesions after 6 months.

\section{SPARCC score}

Patients with a positive MRI at baseline showed a median SPARCC score of the SIJ of 10.0 (IQR 4.0-25.0) and for the spine of 10.0 (IQR 7.0-16.0). Although not significant, male 
Table 1 Patient characteristics of 70 non-radiographic axial SpA patients with high disease activity at baseline: comparison of positive and negative MRI SIJ and/or spine, stratified for sex

$\begin{array}{llll}\text { Total }(N=70) * * & \text { Positive MRI }(N=27) & \text { Negative MRI }(N=42) & P(95 \% \mathrm{CI}) \\ \mathrm{M}(n=33) / \mathrm{F}(n=37) & \mathrm{M}(n=15) / \mathrm{F}(n=12) & \mathrm{M}(n=18) / \mathrm{F}(n=24) & \end{array}$

\section{Demographics}

Male/female (\%)

Age (years)*

Age onset back pain (years)* $(N=68)$

Duration back pain (years)* $(N=68)$

HLA-B27 positive $(N=69)$

\section{NSAID use}

$\mathrm{SpA}$ features

Number SpA features* (mean)

Arthritis

Alternating buttock pain

Dactylitis

Thoracic pain $(N=69)$

Enthesitis Achilles tendon

Enthesitis plantar fascia

Extra-articular symptoms

Uveitis

Inflammatory bowel disease

Psoriasis

Enthesitis

Family history

Ankylosing spondylitis

Psoriasis

Inflammatory bowel disease

Uveitis

Other patient features

BASDAI $(N=61)^{*}$

BASMI $(N=48)^{*}$

Schober $(\mathrm{cm})(N=69) *$

$\operatorname{SJC}(N=68) *$

$\operatorname{TJC}(N=68)^{*}$

$\operatorname{MASES}(N=67) *$

\begin{tabular}{|c|c|c|c|}
\hline $47 / 53$ & $55.6 / 44.4$ & $42.9 / 57.1$ & $0.3(0.2 ; 1.6)$ \\
\hline $34(8.6)$ & $36.1(8.1)$ & $32.6(8.8)$ & $0.1(-7.6 ; 0.76)$ \\
\hline $35.8(8.3) / 32.1(8.7)$ & $39.2(7.3) / 32.3(7.6)^{¥}$ & $33.0(8.2) / 32.4(9.4)$ & \\
\hline $29(9)$ & $30.9(9.2)$ & $27.4(8.8)$ & $0.1(-8.0 ; 1.1)$ \\
\hline $30.8(9.0) / 26.8(8.8)$ & $34.0(9.3) / 27.5(8.1)$ & $28.4(8.3) / 26.7(9.4)$ & \\
\hline $4.7(4.3)$ & $4.7(4.5)$ & $4.8(4.3)$ & $0.9(-2.1 ; 2.3)$ \\
\hline $4.3(3.6) / 5.0(4.9)$ & $4.9(3.9) / 4.5(5.3)$ & $3.9(3.5) / 5.4(4.9)$ & \\
\hline $36(52.2)$ & $13(50.0)$ & $13(50.0)$ & $0.7(0.3 ; 2.2)$ \\
\hline $19(57.6) / 18(50.0)$ & $8(53.3) / 5(45.5)$ & $11(61.1) / 12(50.0)$ & \\
\hline $37(52.9)$ & $16(59.3)$ & $20(47.6)$ & $0.3(0.6 ; 4.3)$ \\
\hline $16(48.5) / 21(56.8)$ & $6(40.0) / 10(83.3)^{¥}$ & $10(55.6) / 10(41.7)$ & \\
\hline $3(1.1)$ & $3.0(1.2)$ & $3.0(1.0)$ & $1.0(-0.5 ; 0.6)$ \\
\hline $2.9(0.9) / 3.1(1.2)$ & $2.9(0.9) / 3.1(1.5)$ & $2.9(1.0) / 3.0(1.1)$ & \\
\hline $22(31.4)$ & $7(25.9)$ & $14(33.3)$ & $0.5(0.2 ; 2.0)$ \\
\hline $10(30.3) / 12(32.4)$ & $5(33.3) / 2(16.7)$ & $5(27.8) / 9(37.5)$ & \\
\hline $45(64.3)$ & $20(74.1)$ & $24(57.1)$ & $0.2(0.7 ; 6.2)$ \\
\hline $18(54.5) / 27(73.0)$ & $10(66.7) / 10(83.3)$ & $8(44.4) / 16(66.7)$ & \\
\hline $5(7.1)$ & $2(7.4)$ & $3(7.1)$ & $1.0(0.2 ; 6.7)$ \\
\hline $2(6.1) / 3(8.1)$ & $0 / 2(16.7)$ & $2(11.1) / 1(4.2)$ & \\
\hline $45(64.3)$ & $16(59.3)$ & $29(70.7)$ & $0.3(0.2 ; 1.7)$ \\
\hline $21(65.6) / 24(64.9)$ & $11(73.3) / 5(41.7)$ & $10(58.8) / 19(79.2)$ & \\
\hline $17(24.2)$ & $5(18.5)$ & $11(26.2)$ & $0.5(0.2 ; 2.1)$ \\
\hline $8(24.2) / 9(24.3)$ & $4(26.7) / 1(8.3)$ & $4(22.2) / 7(29.2)$ & \\
\hline $15(21.4)$ & $6(22.2)$ & $9(21.4)$ & $0.9(0.3 ; 3.4)$ \\
\hline $8(24.2) / 7(18.9)$ & $3(20.0) / 3(25.0)$ & $5(27.8) / 4(16.7)$ & \\
\hline $5(7.1)$ & $2(7.4)$ & $3(7.1)$ & $1.0(0.2 ; 6.7)$ \\
\hline $3(9.1) / 2(5.4)$ & $2(13.3) / 0$ & $1(5.6) / 2(8.3)$ & \\
\hline $3(4.3)$ & 0 & $3(7.1)$ & $0.2(0.9 ; 1.0)$ \\
\hline $2(6.1) / 1(2.7)$ & & $2(11.1) / 1(4.2)$ & \\
\hline $8(11.4)$ & $5(18.5)$ & $3(7.1)$ & $0.2(0.6 ; 13.6)$ \\
\hline $5(15.2) / 3(8.1)$ & $2(13.3) / 3(25.0)$ & $3(16.7) / 0^{¥}$ & \\
\hline $29(42.9)$ & $10(37.0)$ & $19(45.2)$ & $0.5(0.3 ; 1.9)$ \\
\hline $16(48.5) / 13(37.8)$ & $7(46.7) / 3(25.0)$ & $9(50.0) / 10(41.7)$ & \\
\hline $21(30.0)$ & $8(29.6)$ & $13(31.0)$ & $0.9(0.3 ; 2.7)$ \\
\hline $12(36.4) / 9(24.3)$ & $6(40.0) / 2(16.7)$ & $6(33.3) / 7(29.2)$ & \\
\hline $12(17.1)$ & $5(18.5)$ & $7(16.7)$ & $0.8(0.3 ; 4.0)$ \\
\hline $3(9.1) / 9(24.3)$ & $1(6.7) / 4(33.3)$ & $2(11.1) / 5(20.8)$ & \\
\hline $6(8.6)$ & $2(7.4)$ & $4(9.5)$ & $0.8(0.1 ; 4.5)$ \\
\hline $1(3.0) / 5(13.3)$ & $1(6.7) / 1(8.3)$ & $0 / 4(16.7)$ & \\
\hline $2(2.9)$ & $2(5.6)$ & 0 & $0.2(1.0 ; 1.1)$ \\
\hline $1(3.0) / 1(2.7)$ & $1(5.0) / 1(6.3)$ & & \\
\hline $5(2.0)$ & $4.9(1.9)$ & $5.3(2.1)$ & $0.5(-0.7 ; 1.4)$ \\
\hline $4.8(2.0) / 5.3(2.1)$ & $4.4(1.8) / 5.7(1.7)$ & $5.1(2.1) / 5.4(2.1)$ & \\
\hline $1.8(1.2)$ & $1.7(0.9)$ & $1.8(1.4)$ & $0.9(-0.7 ; 0.7)$ \\
\hline $1.8(1.3) / 1.7(1.1)$ & $1.8(1.0) / 1.6(0.9)$ & $1.8(1.5) / 1.8(1.2)$ & \\
\hline $4.4(1.0)$ & $4.2(0.9)$ & $4.5(0.9)$ & $0.2(-0.2 ; 0.7)$ \\
\hline $4.4(0.9) / 4.4(0.9)$ & $4.1(0.9) / 4.3(1.1)$ & $4.7(0.9) / 4.4(0.9)$ & \\
\hline $0.2(0.5)$ & $0.2(0.7)$ & $0.1(0.4)$ & $0.5(-0.4 ; 0.2)$ \\
\hline $0.3(0.2) / 0.3(0.7)^{\ddagger}$ & $0 / 0.5(1.0)$ & $0.06(0.2) / 0.2(0.5)$ & \\
\hline $2(4)$ & $1.0(2.2)$ & $2.6(4.5)$ & $0.1(-0.0 ; 3.2)$ \\
\hline $2.1(4.5) / 1.8(3.2)$ & $0.6(2.3) / 1.6(0.9)$ & $3.4(5.5) / 2.0(3.7)$ & \\
\hline $6.8(7.4)$ & $3.8(4.3)$ & $9.1(8.4)$ & $0.001(2.1 ; 8.4)^{¥}$ \\
\hline $5.1(7.4) / 8.3(7.2)$ & $2.2(3.3) / 5.8(4.8)^{\ddagger}$ & $7.7(9.0) / 10.1(7.9)$ & \\
\hline
\end{tabular}


Table 1 (continued)

\begin{tabular}{|c|c|c|c|c|}
\hline & $\begin{array}{l}\text { Total }(N=70) * * \\
\mathrm{M}(n=33) / \mathrm{F}(n=37)\end{array}$ & $\begin{array}{l}\text { Positive MRI }(N=27) \\
\mathrm{M}(n=15) / \mathrm{F}(n=12)\end{array}$ & $\begin{array}{l}\text { Negative MRI }(N=42) \\
\mathrm{M}(n=18) / \mathrm{F}(n=24)\end{array}$ & $P(95 \% \mathrm{CI})$ \\
\hline $\operatorname{ESR}(\mathrm{mm} / \mathrm{h})(N=67)^{*}$ & $\begin{array}{l}10.7(10) \\
7.2(9.4) / 13.6(9.6)\end{array}$ & $\begin{array}{l}11.1(10.9) \\
8.8(12.1) / 13.8(9.2)\end{array}$ & $\begin{array}{l}10.3(9.5) \\
5.8(6.4) / 13.5(10.2)^{\ddagger}\end{array}$ & $0.8(-5.8 ; 4.3)$ \\
\hline $\mathrm{CRP}(\mathrm{mg} / \mathrm{l})(N=66)^{*}$ & $\begin{array}{l}3.7(5.5) \\
2.6(4.6) / 4.6(6.1)\end{array}$ & $\begin{array}{l}4.0(6.0) \\
3.1(5.6) / 5.1(6.5)\end{array}$ & $\begin{array}{l}3.6(5.4) \\
2.2(3.5) / 4.8(6.2)\end{array}$ & $0.8(-3.2 ; 2.5)$ \\
\hline CRP (mg/l) elevated (\%) & $\begin{array}{l}22(31.4) \\
9(27.3) / 13(35.1)\end{array}$ & $\begin{array}{l}9(39.1) \\
5(33.3) / 4(33.3)\end{array}$ & $\begin{array}{l}13(27.7) \\
4(22.2) / 9(37.5)\end{array}$ & $0.9(0.4 ; 3.0)$ \\
\hline
\end{tabular}

** included were 70 patients, of whom 69 had completed data sets of the MRI of the SIJ and spine. If not stated otherwise, all displayed values are listed in whole numbers with matching percentages in brackets. Parameters labelled with * are listed as mean value with standard deviation in brackets. Positive MRI means inflammation on MRI SIJ and/or spine at baseline. Negative MRI means no inflammation on MRI SIJ and/or spine at baseline. For some variables, sample size deviates from the original 70 patients. For these variables, the actual sample size is stated in brackets after the variable name. $\$$ indicate a significant difference of $p<0.05$. HLA-B27 human leukocyte antigen (B27), NSAIDs non-steroidal anti-inflammatory drugs, SpA spondyloarthritis, IBD inflammatory bowel disease, BASDAI Bath Ankylosing Spondylitis Disease Activity Index, BASMI Bath Ankylosing Spondylitis Metrology Index, SJC swollen joint count, TJC tender joint count, MASES Maastricht Ankylosing Spondylitis Enthesitis Score, ESR erythrocyte sedimentation rate, $C R P$ C-reactive protein, $M$ male, $F$ female, $C I$ confidence interval

patients revealed a higher median SPARCC score of the SIJ and spine compared with females, 14.0 (IQR 2.3-25.0) vs. 10.0 (IQR 6.5-22.5) and 11.5 (IQR 8.5-25.6) vs. 8.0 (IQR $5.5-14.5$ ), respectively (Table 2 ).

\section{Comparison of MRI outcomes}

Only a lower MASES score was significantly associated with a positive MRI outcome in logistic regression analyses $(\beta=-$ $0.02,95 \%$ CI $[-0.04 ;-0.01], p=0.004$ ) (Table 1 ). Adjustment for sex, NSAID use at baseline and HLA-B27 status made no difference in the found association.

\section{Structural changes}

Overall, 17 MRIs of the spine and SI joints showed structural changes in 14 patients (20\%), of whom 11 patients were male.

Table 2 SPARCC scores of the MRIs of 27 patients showing signs of inflammation, stratified for gender

\begin{tabular}{lll}
\hline & Male & Female \\
\hline Positive MRI (27 patients) (\%) & 45.5 & 33.3 \\
SIJ (21 patients) (\%) & 37.5 & 25.0 \\
Spine (9 patients) (\%) & 20.0 & 18.5 \\
SIJ and spine (3 patients) (\%) & 3.0 & 5.6
\end{tabular}

SPARCC score in positive MRI (median, IQR) (27 patients)

SIJ (median score $10.0(4.0-25.0)^{*} \quad 14(2.3-25.0) \quad 10(6.5-22.5)$

Spine (median score 10.0 (7.0-16.0) $11(8.5-25.6) \quad 8.0(5.5-14.5)$

Conversion to positive MRI after 6 months follow-up (1 out of 21 patients)*
SIJ $N(\%)$
0
$1(4.7 \%)$

SIJ sacroiliac joint, SPARCC Spondyloarthritis Research Consortium of Canada. Positive SPARCC score $\mathrm{SIJ} \geq 2$, positive SPARCC score spine $\geq$ 5 , *No new inflammatory signs at the MRI spine were detected after 6 months
The majority of these patients $(N=11)$ showed a combination of inflammatory and structural lesions in both the spine and SIJ. The most frequently recorded structural change was fat infiltration in both the spine (5 patients) and SIJ (1 patient). One patient had fatty infiltration in both the spine and SIJ (global fat infiltration). In the spine, fatty infiltration was found at several places, such as antero-inferior endplates, anterior corner and postero-superior endplate ranged L3-S1. Two patients showed doubtful erosions in the lower ilium. In addition, Schmorl's nodes were seen in three patients located in the Th8-Th12 region of the spine.

Importantly, even in patients with a negative MRI $(N=3)$, several structural changes were noted. In two patients, fat infiltration was observed in the spine, whereas one patient showed Schmorl's nodes at the superior endplates of Th8 and Th11.

\section{Sacroiliitis on MRI according to the ASAS criteria}

Sacroiliitis on MRI was present in 21 patients, of whom 11 patients showed unilateral and 10 patients bilateral sacroiliitis. Although not significant, more male patients had sacroiliitis compared with females, $37.5 \%$ vs. $21.6 \%$, respectively.

\section{ASAS classification of axial SpA}

Twenty-six patients did not fulfil the nr-axSpA criteria, although the clinical presentation was highly suspicious of axial SpA. Twenty-three patients (52.3\%) only fulfilled the "clinical arm". In addition, 21 of the 44 patients (47.7\%) fulfilled the "imaging arm" of the ASAS criteria, of whom 11 patients also fulfilled the criteria for the "clinical arm". More male patients fulfilled the ASAS criteria imaging arm compared with females, $39.4 \%$ vs. $27.0 \%$. 


\section{Discussion}

In 69 patients with IBP and at least two SpA features and a high disease activity, $39 \%$ of patients showed signs of active inflammation (BME) according to the SPARCC score on MRI scans, primarily of the SI joints (88\%) and a few of the spine. Only one patient conversed from a negative MRI at baseline to a positive MRI of the SI joints after 6 months, whereas no new lesions of the spine were detected after follow-up. Structural lesions, mainly of the spine, were present in $20 \%$ of the patients, most often in combination with signs of active inflammation, both in the spine and SIJ, but also in three patients without BME.

The number of positive MRIs is comparable with that in other study results in IBP patients, which showed prevalence between 26 and $41 \%[4,5]$. The difference might be explained by the fact that our population had a high disease activity and shows results that are comparable with baseline data from clinical trials with biologicals, showing positive MRIs in $67 \%, 54 \%$ or $48 \%$ of the axial SpA patients [15-17]. However, in the SPACE cohort, which included patients with chronic back pain ( $>3$ months, $<2$ years and onset $<45$ years), a positive MRI of the SIJ was found in only $25 \%$ of the patients [18], which is much lower compared with our findings (39\%). This difference can be explained by the high disease activity on our group, the presence of more SpA features, the addition of the MRI spine, which was positive in $19 \%$ of the patients with negative SIJ images, and the use of gadolinium, an intravenous contrast that enhances the quality of the MRI. The use of intravenous contrast in MRI scans of the spine and SI joints is a method that was used in the past. In selected cases, when high STIR signal in the joint is the only finding, gadolinium-enhanced images may help to confirm the presence of synovitis. However, in our study, this was not the case and the use of gadolinium for the axSpA images is abandoned nowadays.

The level of inflammation, measured with the SPARCC score, showed a mean score of 10.0 for the SI joints and 10.0 for the spine. Comparison with other studies in $\mathrm{nr}$ axSpA showed contradictory results. Two studies showed comparable results: 7.2 and 7.4 for SIJ and 7.2 for spine $[19,20]$, whereas two others showed lower SPARCC scores: SIJ 4.7 and 4.9 and spine 4.3 and 4.6 , respectively $[15,21]$. There were no demographical features or baseline data (e.g. disease activity) that could explain the differences with our study results.

Only one patient $(4.7 \%)$ with a negative MRI at baseline conversed to a positive MRI after 6 months. Other studies showed comparable numbers, $4-15 \%$, of conversion of negative to positive MRIs [4, 18]. These low numbers of conversion of a negative to a positive MRI after a short interval period indicate that it is not efficient to repeat a MRI within 6 months. These results were confirmed by the SPACE cohort, which indicated that repetition of MRI scans at 3 months and 1 year was not useful [22].

Assessment of gender differences revealed that male patients, in general, more frequently had a positive MRI compared with females, $45.5 \%$ vs. $33.3 \%$, respectively. In addition, the majority of patients with structural lesions was male $(11 / 14=78.6 \%)$, which corresponds to a study by Maksymowych [23]. These results are in line with the limited studies available assessing gender differences and MRI findings in nr-axSpA patients, which indicate that male gender, especially in the case of HLA-B27 positivity, is a predictor for a positive MRI outcome [4]. Assessment of gender differences in the SPARCC scores in our study revealed that male patients had a higher median SPARCC score of the SIJ and spine compared with females, 14.0 vs. 10.0 and 11.5 vs. 8.0, respectively. Consistently, male patients also showed more often sacroiliitis at MRI, according to the ASAS definition, compared with females, $37.5 \%$ vs. $21.6 \%$.

The question remained if MRI of the spine had an additional value to the MRI of the SIJ. In our own study, the number of positive MRIs of the spine was almost $20 \%$. In addition, only three patients presented with a positive MRI of both the spine and SIJ. These results might indicate an additional value for the MRI of the spine. However, these numbers are in contradiction with a couple of other studies that assessed the diagnostic value of MRI of the spine [24, 25]. Weber et al. revealed that the combined MRI (spine and SIJ) seemed to increase the percentage of identifications of nraxSpA patients and also showed false positive results in an equal percentage in the control groups (non-specific back pain and inflammatory back pain patients). These misclassifications neutralized the additional diagnostic value of combined MRI in patients with nr-axSpA and seemed to have no contribution to the diagnosis $[24,25]$.

Our study included a unique population of patients suspected of nr-axSpA with a high disease activity (BASDAI $\geq 4$ ). For this reason, our results differ slightly from those of other studies conducted in a population that fulfilled the ASAS criteria. However, the numbers of specific SpA features were too small to assess them for possible associations with a positive or negative MRI. In this study, we have used the ESSG criteria and BASDAI instead of the ASAS classification criteria and ASDAS response, which we would have chosen nowadays. However, the study was developed in a period (2004) when these classification criteria and outcome parameters were much less often used as they currently are. In addition, as we mentioned in the "Introduction", the MRI images of the SI joints are one of the major criteria in the ASAS classification criteria, whereas the primary aim of our study was to find out how often these images were positive in cases with a high risk at axial SpA. Considering the current debate around the value of all separate classification parameters in axial $\mathrm{SpA}$, the MRI results of a slightly different group 
of back pain patients might help in the discussion around the added value of MRI in this group from a different perspective.

This study has several limitations. Apart from the inclusion criteria and disease activity parameters, which differ from the currently used criteria, we had only one assessor of the MRIs, who performed the SPARCC scores, and all MRIs were also assessed by the musculoskeletal radiologist of the university medical centre. In addition, we have not repeated the MRIs in all patients after 6 months, but only in those who did not show inflammatory lesions at baseline. Another limitation is the lower number of patients who underwent the MRI of the spine compared with the SIJ because they refused to undergo this procedure. However, the number of images of the SIJ is high enough to draw conclusions on the presence of inflammation in this group with high disease activity.

In summary, the results of this study show that in this specific group of patients with inflammatory back pain, a high BASDAI score and those who are either HLA-B27 positive and have one additional SpA feature or HLA-B27 negative with two additional SpA features have a number of positive MRI results of the SI joints. All patients with a positive MRI were included in a placebo-controlled trial with etanercept (the PREVAS study) of which the results will be presented soon. In our opinion, the MRI of the spine is of limited value in addition to the MRI SIJ for the assessment of disease activity and repetition of the MRI after 6 months of the SI joints, in case of absence of inflammation, is not warranted either.

In conclusion, almost $40 \%$ of the patients with inflammatory back pain and high disease activity showed inflammatory lesions on MRI of the SIJ and/or spine, which occurred more often in males compared with females. In most cases (95.3\%), a MRI without inflammatory lesions remained negative after 6 months, which suggests that a second MRI scan after only 6 months is not valuable.

\section{Compliance with ethical standards}

Conflict of interest Tamara Rusman: none, Marie-Luise B. John: none, Mignon A.C. van der Weijden: none, Bouke J.H. Boden: none, Carmella M.A. van der Bijl: none, Stefan T.G. Bruijnen: none, Conny J. van der Laken: none, Mike T. Nurmohamed: none, Irene E. van der HorstBruinsma: Abbvie, UCB, MSD, Novartis, Lilly, Pfizer, BMS.

Ethical statements The study complied with the Declaration of Helsinki and its later amendments and was approved by our local ethical committee of the VU University Medical Center (approval number medical ethical committee 2009/206) and all patients signed an informed consent before screening.

Open Access This article is licensed under a Creative Commons Attribution 4.0 International License, which permits use, sharing, adaptation, distribution and reproduction in any medium or format, as long as you give appropriate credit to the original author(s) and the source, provide a link to the Creative Commons licence, and indicate if changes were made. The images or other third party material in this article are included in the article's Creative Commons licence, unless indicated otherwise in a credit line to the material. If material is not included in the article's Creative Commons licence and your intended use is not permitted by statutory regulation or exceeds the permitted use, you will need to obtain permission directly from the copyright holder. To view a copy of this licence, visit http://creativecommons.org/licenses/by/4.0/.

\section{References}

1. Rudwaleit M, van der Heijde D, Landewe R, Listing J, Akkoc N, Brandt J et al (2009) The development of Assessment of SpondyloArthritis international Society classification criteria for axial spondyloarthritis (part II): validation and final selection. Ann Rheum Dis 68:777-783

2. Rudwaleit M, Sieper J (2012) Referral strategies for early diagnosis of axial spondyloarthritis. Nat Rev Rheumatol 8:262-268

3. Poddubnyy D, Rudwaleit M, Haibel H, Listing J, Marker-Hermann E, Zeidler $\mathrm{H}$ et al (2011) Rates and predictors of radiographic sacroiliitis progression over 2 years in patients with axial spondyloarthritis. Ann Rheum Dis 70:1369-1374

4. van Onna M, Jurik AG, van der Heijde D, van Tubergen A, HeuftDorenbosch L, Landewe R (2011) HLA-B27 and gender independently determine the likelihood of a positive MRI of the sacroiliac joints in patients with early inflammatory back pain: a 2-year MRI follow-up study. Ann Rheum Dis 70:1981-1985

5. van den Berg R, de Hooge M, Rudwaleit M, Sieper J, van Gaalen F, Reijnierse M, Landewé R, Huizinga T, van der Heijde D (2013) ASAS modification of the Berlin algorithm for diagnosing axial spondyloarthritis: results from the SPondyloArthritis Caught Early (SPACE)-cohort and from the Assessment of SpondyloArthritis international Society (ASAS)-cohort. Ann Rheum Dis 72:16461653

6. Calin A, Porta J, Fries JF, Schurman DJ (1977) Clinical history as a screening test for ankylosing spondylitis. JAMA 237:2613-2614

7. van der Linden S, Valkenburg HA, Cats A (1984) Evaluation of diagnostic criteria for ankylosing spondylitis. A proposal for modification of the New York criteria. Arthritis Rheum 27:361-368

8. Rudwaleit M, van der Heijde D, Khan MA, Braun J, Sieper J (2004) How to diagnose axial spondyloarthritis early. Ann Rheum Dis 63: $535-543$

9. Sieper J, Rudwaleit M (2005) Early referral recommendations for ankylosing spondylitis (including pre-radiographic and radiographic forms) in primary care. Ann Rheum Dis 64:659-663

10. Bruijnen ST, van der Weijden MA, Klein JP, Hoekstra OS, Boellaard R, van Denderen JC et al (2012) Bone formation rather than inflammation reflects ankylosing spondylitis activity on PETCT: a pilot study. Arthritis Res Ther 14:R71

11. Maksymowych WP, Inman RD, Salonen D, Dhillon SS, Krishnananthan R, Stone M, Conner-Spady B, Palsat J, Lambert RG (2005) Spondyloarthritis Research Consortium of Canada magnetic resonance imaging index for assessment of spinal inflammation in ankylosing spondylitis. Arthritis Rheum 53:502-509

12. Maksymowych WP, Inman RD, Salonen D, Dhillon SS, Williams M, Stone M, Conner-Spady B, Palsat J, Lambert RG (2005) Spondyloarthritis Research Consortium of Canada magnetic resonance imaging index for assessment of sacroiliac joint inflammation in ankylosing spondylitis. Arthritis Rheum 53:703-709

13. Rudwaleit M, Jurik AG, Hermann KG, Landewe R, van der Heijde D, Baraliakos X et al (2009) Defining active sacroiliitis on magnetic resonance imaging (MRI) for classification of axial spondyloarthritis: a consensual approach by the ASAS/ OMERACT MRI group. Ann Rheum Dis 68:1520-1527 
14. van den Berg R, de Hooge M, Bakker PA, van Gaalen F, NavarroCompan V, Fagerli KM et al (2015) Metric properties of the SPARCC score of the sacroiliac joints-data from baseline, 3-month, and 12-month followup in the SPACE cohort. J Rheumatol 42: $1186-1193$

15. Sieper J, van der Heijde D, Dougados M, Mease PJ, Maksymowych WP, Brown MA, Arora V, Pangan AL (2013) Efficacy and safety of adalimumab in patients with non-radiographic axial spondyloarthritis: results of a randomised placebo-controlled trial (ABILITY-1). Ann Rheum Dis 72:815-822

16. Landewe R, Braun J, Deodhar A, Dougados M, Maksymowych WP, Mease PJ et al (2014) Efficacy of certolizumab pegol on signs and symptoms of axial spondyloarthritis including ankylosing spondylitis: 24-week results of a double-blind randomised placebo-controlled phase 3 study. Ann Rheum Dis 73:39-47

17. Sieper J, van der Heijde D, Dougados M, Maksymowych WP, Scott $\mathrm{BB}$, Boice JA et al (2015) A randomized, double-blind, placebocontrolled, sixteen-week study of subcutaneous golimumab in patients with active nonradiographic axial spondyloarthritis. Arthritis Rheumatol 67:2702-2712

18. Bakker PA, Ez-Zaitouni Z, van Lunteren M, van den Berg R, De Hooge M, Fagerli KM et al (2016) Are additional tests needed to rule out axial spondyloarthritis in patients ages 16-45 years with short-duration chronic back pain and maximally one spondyloarthritis feature. Arthritis Care Res (Hoboken) 68:17261730

19. Braun J, Baraliakos X, Hermann KG, Landewe R, Machado PM, Maksymowych WP et al (2017) Effect of certolizumab pegol over 96 weeks of treatment on inflammation of the spine and sacroiliac joints, as measured by MRI, and the association between clinical and MRI outcomes in patients with axial spondyloarthritis. RMD Open 3:e00430

20. Maksymowych WP, Dougados M, van der Heijde D, Sieper J, Braun J, Citera G, van den Bosch F, Logeart I, Wajdula J, Jones
H, Marshall L, Bonin R, Pedersen R, Vlahos B, Kotak S, Bukowski JF (2016) Clinical and MRI responses to etanercept in early nonradiographic axial spondyloarthritis: 48-week results from the EMBARK study. Ann Rheum Dis 75:1328-1335

21. van der Heijde D, Sieper J, Maksymowych WP, Lambert RG, Chen S, Hojnik M et al (2018) Clinical and MRI remission in patients with nonradiographic axial spondyloarthritis who received longterm open-label adalimumab treatment: 3-year results of the ABILITY-1 trial. Arthritis Res Ther 20:61

22. Bakker PA, Ramiro S, Ez-Zaitouni Z, van Lunteren M, Berg IJ, Landewe $\mathrm{R}$ et al (2019) Is it useful to repeat MRI of the sacroiliac joints after three months or one year in the diagnostic process of patients with chronic back pain suspected of axial spondyloarthritis. Arthritis Rheumatol 71:382-391

23. Maksymowych WP, Wichuk S, Dougados M, Jones H, Szumski A, Bukowski JF et al (2017) MRI evidence of structural changes in the sacroiliac joints of patients with non-radiographic axial spondyloarthritis even in the absence of MRI inflammation. Arthritis Res Ther 19:126

24. Weber U, Zubler V, Zhao Z, Lambert RG, Chan SM, Pedersen SJ, Østergaard M, Rufibach K, Maksymowych WP (2015) Does spinal MRI add incremental diagnostic value to MRI of the sacroiliac joints alone in patients with non-radiographic axial spondyloarthritis. Ann Rheum Dis 74:985-992

25. Ez-Zaitouni Z, Bakker PA, van Lunteren $M$, de Hooge $M$, van den Berg R, Reijnierse M et al (2017) The yield of a positive MRI of the spine as imaging criterion in the ASAS classification criteria for axial spondyloarthritis: results from the SPACE and DESIR cohorts. Ann Rheum Dis 76:1731-1736

Publisher's note Springer Nature remains neutral with regard to jurisdictional claims in published maps and institutional affiliations. 